\title{
LXXXVIII. Some experiments and researches on the saline contents of sea-water, undertaken with a view to correct and improve its chemical analysis
}

\section{Alexander Marcet M.D. F.R.S.}

To cite this article: Alexander Marcet M.D. F.R.S. (1822) LXXXVIII. Some experiments and researches on the saline contents of sea-water, undertaken with a view to correct and improve its chemical analysis, Philosophical Magazine Series 1, 60:296, 434-440, DOI: 10.1080/14786442208644241

To link to this article: http://dx.doi.org/10.1080/14786442208644241

进 Published online: 29 Jul 2009.

Submit your article to this journal \ulcorner

Ш Article views: 2

View related articles $\sqsubset$ 
tion, even on the supposition that it pleases Heaven to preserve me in health and vigour, cannot yet be determined. As, however, it is desirable that it should not be very long delayed, I rejoice to have found Professor Struve of Dorpat, and Dr. Walbeck of Abo, willing to undertake a part of the labour, as soon as they are in possession of the requisite means. Other fellow labourers, provided with equally good and powerful meridian circles, will be very desirable; and I am ready to make the necessary arrangement concerning the choice of a region of the heavens. At a time when an Astronomical Society has been instituted, whose principal object is a minute investigation of the heavens, I think that the hope of seeing this plan realized in its fullest extent cannot be deemed altogether extravagant.

[Professor Bessel has subjoined to this valuable paper a copious list of the stars already observed by him; but which we are obliged to omit for want of room. The appeal which is made, in the last sentence, to the Astronomical Society of London, we hope will not be made in vain.-EDIr.]

LXXXVIII. Some Experiments and Researches on the Saline Contents of Sea-Water, undertaken with a view to correct and improve its Chemical Analysis. By Alexander Marcet, M.D. F.R.S. Honorary Professor of Chemistry at Geneva*.

$\mathbf{I}_{\mathrm{N}}$

$\mathrm{N}$ a paper on the temperature and saltness of various seas, which the Roynl Society did me the honour to publish in their Transactions for the year 1819, I threw out a conjecture, that the sea might contain minute quantities of every substance in nature, which is soluble in water. For the ocean having communication with every part of the earth through the rivers, all of which ultimately pour their waters into it; and soluble substances, even such as are theoretically incompatible with each other, being almost in every instance capable of co-existing in solution, provided the quantities be very minute, I could see no reason why the ocean should not be a general receptacle of all bodies which can be held in solution. And although it will appear from the following account, that I have been unsuccessful in some of my attempts to prove the truth of this conjecture, it may fairly be ascribed either to a want of sufficient accuracy in our present methods of chemical analysis, or of the requisite degree of skill in the operator.

* From the Transactions of the Philosophical Society, Part I. for 1822. 
Some time after the communication to which I have just referred, an extraordinary statement was pointed out to me, upon the authority of Rouelle, a French chemist of the last century, from which it appeared that mercury was contained in sea salt*: and I saw soon after in the 'Annales du Musée,' vol. vii. a paper by the celebrated chemist Proust, who, in a great measure, confirmed that statement, by announcing that he had found traces of mercury in all the specimens of marine acid which he had examined.

Improbable as the fact appeared, I thought it worth while to repeat the experiment, and to take that opportunity of making some collateral researches upon other substances, much more likely than mercury to be discovered in sea-water.

For this purpose I availed myself of the kindness of my friend Mr. John Barryt, who happened to be in the vicinity of Portsmouth, to supply me with specimens of sea-water, carefully concentrated upon the spot, in vessels of Wedgwood ware, and with scrupulous attention to cleanliness in the process. Accordingly he was so obliging, as not only to send me a quantity of brine evaporated under his own eye, in the manner just mentioned, but he also collected for me a valuable series of specimens from the salt-works near Portsmouth, from all the stages of the process, so as to afford me an opportunity of investigating with accuracy all the chemical circumstances of this interesting branch of national œeconomy. Finding myself, however, much pressed by time at this late period of the session, I shall, after briefly adverting to Rouelle's supposed discovery, confine myself in this communication to a few observations which I have made on sea-water itself; keeping out of view, for the present, the topic of salt-making, which, however, $I$ intend to resume at some future period, in a more complete and satisfactory manner.

I first attempted to detect mercury in a specimen of bay-salt, such as is obtained in the salt-works near Portsmouth, by spontaneous. evaporation. This variety of salt forms large crystals, but is always more or less contaminated by earthy matter, which gives it a dirty appearance. It has, probably, a general resemblance to the French Sel de Gabelle, which is more impure still, though, I believe, obtained in a similar mannert.

* See Journal de Médecine, vol. xlviii. 1777, page 322.

+ Mr. Joln Barry, of Plough Court, inventor of a new and valuable process for preparing extracts in vacuo, \&c.

$\neq$ The name of bay-salt is often applied to foreign as well as British salt, and in general it simply denotes that the salt has been obtained by spontaneous evaporation. 
Eight ounces of this salt were put into a coated retort connected with a receiver, and about four ounces of nitrous acid were poured upon it. A pretty brisk action tock place, which was further increased by the application of heat; fumes of chlorine were immediately disengaged, and a reddish fluid condensed in the receiver; the heat was continued, and gradually raised in a charcoal fire till no acid or moisture any longer came over; at which time a new emission of red fumes indicated that the nitrate formed in the retort was beginning to part with its acid; minute drops of fused salt soon bedewed the upper part and neck of the retort, so as to be mistaken, at first, for a sublimate. This, however, proved to be almost solely muriate of soda; and on careful examination, it did not appear to contain the smallest atom of corrosive sublimate.

I next dissolved five or six pounds of bay-salt in water, and collected in a filter the insoluble earthy sediment, in which Rouelle stated that the quicksilver was usually found. This sediment being carefully dried, and heated to redness in a coated retort, a white sublimate arose, and condensed on the neck of the retort; but this sublimate proved to be muriate of ammonia, and did not contain the smallest portion of corrosive sublimate or other mercurial salt. This sal-ammoniac, though evidently formed during the distillation from the vegetable and animal matter contained in the sediment, suggested to me the idea of looking for ammonia amongst the contents of seawater,

I now submitted some Sel de Gabelle, which I had procured from Calais for the purpose, to similar experiments, and the sediment, also was carefilly examined. The result was essentially the same as with the bay-salt. After adding nitric acid to the salt, the heat was gradually pushed to redness; and when all the moisture was evaporated, a white sublimate appeared, as in the former case, which, in this instance, proved to consist almost entirely of nitrate of soda; but always without the least particle of mercurial salt, and without any muriate of ammonia*.

I therefore think myself justified in concluding that the mercury, which other chemists have detected in sea-salt or its products, must have been introduced there from some local or accidental circumstances.

In experiments upon sea-salt, or in general upon the saline contents of the sea, it is obvious that, in order to exclude

* In the former experiment the sublimate was principally muriate of soda, owing, no doubt, to the decomposition having been less complete, and the operation less gradually conducted than in the latter experiment.

sources 
sources of error, it is necessary to operate upon pure seawater, and not upon salts obtained from it by the usual processes in the large way, these being always more or less contaminated by the clay pits in which the evaporation is carried on, by the metallic boilers, or other adventitious causes. I therefore now turned my attention to the sea-water itself, and in particular the perfectly pure and transparent specimen of concentrated brine from the Channel, which I have above mentioned. Mr. Barry procured this water near Bembridge floating light, about two miles N.E. of the eastern extremity of the Isle of Wight, and the evaporation which it had undergone at Portsmouth had only separated from it a quantity of calcareous matter, principally selenite *

A few pounds of this water were cvaporated ncariy to dryness, at a gentle heat, so as to reduce the mother liquor to the smallest possible quantity. This licuor was suffered to drain off, and reserved for experiments, as it is in this fluid that any new ingredients are most likely to be detected.

I had suspected that some nitric salt might be found in seawater; but in this I was disappointed. The discrimination by the shape of the crystals being in this instance scarcely practicable, the mode which I employed for detecting it, consisted in concentrating the bittern in a glass tube or retort, till it began to deposit solid matter, then adding sulphuric acid and gold-leaf, and boiling the mixture; the gold-leaf was not in the least acted upon, nor was any smell of nitric acid perceived; but on adding the smallest quantity of nitre to the same mixture, the gold was dissolved, and the smell of aqua regia was instantly perceived + .

A portion of the said bittern was next examined by appro. priate re-agents with a view to detect any minute quantity of earths or metals, especially alumina, silica, iron and copper, which former inquirers might have overlooked; but I could find no other earth except magnesia: and to my surprise, I did not find in the bittern the least particle of lime; which proves that sea-water contains no muriate of lime, as had been generally supposed. I was equally unsuccessful in my attempts to detect iron or copper, by the most delicate tests.

* The water, immediately on being raised from the sea, had been allowed to stand a sufficient time to deposit the earthy particles suspended in it, by which means it had become beautifully transparent. 100 pounds of the water produced only three grains of carthy sediment, in which I could discover nothing but carbonate of lime and oxide of iron. It is in this sediment, according to Rouelle, that mercury is to be found. I need hardly say that I could not detect in it the least particle of that metal.

+ For this easy and elegant process for detecting nitric acid, a point attonded with difficulty, I am indebted to Dr. Wollaston. 
In fact, neither alkalies, nor alkaline carbonates, precipitated any other substance from the bittern of sea-water, except magnesia.

The deposit obtained at Portsmouth during the early period of the concentration of the water, being analysed, I found it to consist of selenite, mixed with a little muriate of soda, and a portion of carbonate of lime. The presence of this last substance in sea water, in a state of perfect solution, being, I believe, a new fact, I neglected no means of establishing it with certainty, an object which was accomplished without diffculty*.

Carbonate of magnesia having been supposed by some chemists to exist in sea-water, I looked for it in the same deposit; but I could not detect the least portion of it by the most delicate testst.

I next turned my attention to the alkaline salts of sea-water: and here I was more fortunate; as I succeeded in ascertaining beyond a doubt, that sea-water contains ammonia, as it yielded sal-ammoniac by evaporation and sublimation. This result was easily obtained. Some of the bittern being evaporated to dryness in a retort, and a low red heat applied, a white sublimate appeared in the neck of the retort, which proved to be muriate of ammonia. The mode in which this substance was identified was as follows :

1. The sublimate was re-dissolved in water, re-evaporated to dryness, and again sublimed by the heat of a spirit-lamp.

2. This new sublimate being again dissolved, and solution of magnesia and phosphoric acid added, a triple phosphate was formed.

3. On adding caustic potash to the solution, and bringing the mouth of a phial containing muriatic acid close to the vessel, abundant white fumes appeared.

4. The sublimate gave precipitates both with muriate of platina and nitrate of silver $\neq$.

Sulphate of soda having been mentioned by many chemists, as one of the constituents of sea-water, I endeavoured to as-

* The deposit was treated with acetic acid, which occasioned an effervescence. The clear liquor being then decanted off, and evaporated to dryness, and alcohol added, acetate of lime was fourd in the filtered alcoholic liquor.

+ Namely, solution of the mass in dilute muriatic acid; precipitation of the lime, and addition of phosphate of ammonia to the filtered liquor.

$\neq$ As it did not enter into my plan, on this occasion, to turn my attention to the estimation of proportions or precise quantities, I have not attempted to estimate exactly the proportion which ammonia bears to the other ingredients of sea-water; but as its presence can easily be shown in 100 grains of the bitter salts, its quantity cannot be extremely minute.

certain, 
certain, whether or not it existed in it. But all attempts to detect this salt in the bittern by crystallization were fruitless, though great pains were taken for that purpose; and I feel the more confident that there is no sulphate of soda in sea-water, as the presence of this salt, in any but the most minute quantities, would be quite incompatible with our knowledge of chemical affinities. For since there are, co-existing in seawater, muriate of soda and sulphate of magnesia, it is evident that sulphate of soda would decompose muriate of magnesia, which salt is known to be in sea-water. And again we know, that sea-water contains sulphate of lime and muriate of soda; therefore it cannot contain sulphate of soda; for in that case we should have muriate of lime, which $I$ have shown to be contrary to fact.

The last circumstance which I shall at present notice, relates to the state in which potash exists in sea-water*. Potash is found, by its appropriate re-agents, principally in the bittern; but it is found also among the salts which are separated from it, especially in the latter period of crystallization. By further and repeated evaporation of the bittern, and successive separation of the mother-water remaining after the removal of the crystals formed, various distinct crystals were obtained possessing their characteristic form, namely, prismatic sulphate of magnesia, cubic and star-shaped muriate of soda, and rhombic crystals, quite different from either of the other salts. These crystals, which were evidently portions of an oblique rhombic prism, being carefully separated and washed with water and alcohol, proved to be a triple salt of sulphate $r f$ potash and magnesia; a salt so easily analysed, that it would be quite superfinous to relate the particulars of the process.

It now remained to be ascertained, whether potash might not also exist in sea-water in the state of muriate of potash, or of triple muriate of potash and magnesia. That a considerable quantity of potash remains in the bittern, even after the separation of the triple sulphate, is easily ascertained; and by careful evaporation it may be made to crystallize as a triple salt in rhombic crystals; but the constitution of this salt is so delicate, that it is liable to be separated into muriate of potash and muriate of magnesia by water alone; and it is with certainty decomposed by alcohol, which takes up the magnesian muriate, and leaves the other undissolved.

* It will be recollected, that the presence of potash in sea-water, though announced by myself in the paper on sea-water to which $I$ have before alluded, was Dr. Wollaston's discovery. I have likewise to mention, that the above experiments respecting the state in which it exists, were either made by him or at his suggestion. 
From the foregoing observations and experiments it may, therefore, be inferred,

1st. That there is no mercury, or mercurial salt, in the waters of the ocean.

$2 \mathrm{dly}$. That sea-water contains no nitrates.

3 dly. That it contains sal-ammoniac.

4thly. That it holds carbonate of lime in solution.

5thly. That it contains no muriate of lime.

6 thly. That it contains a triple sulphate of magnesia and potash.

Some of these circumstances will, of course, require that former analyses of sea-water, and my own in particular, should be corrected and revised; but this I shall not attempt to do, until I have obtained further and still more precise information on the subject.

Harley-street, June 20, 1822.

LXXXIX. On the visible Solar and Lunar Eclipses rohich will happen in the Year 1823, as calculated for Greenwich and Aberdeen; the Elements being calculated from the Tables of $M$. Delanime and $M$. Burckhardt. By Mr. George INNes *.

[The times are inserted according to civil account, the day being reckoned to begin at midnight.]

To the Editors of the Philosophical Magazine and Journal.

Gentremen, - I calculating the two lunar eclipses, I have increased the moon's equatorial parallax $\frac{1}{6} 0$ part for the refraction of the earth's atmosphere. Astrononers seem doubtful how much is to be added to the semidiameter of the shadow of the eartl as projected at the distance of the moon; but the quantity must certainly bear some proportion to the parallax.

I send you the elements of the solar eclipse, for the use of such as may wish to make a projection; but firom the instant of greatest obscuration falling between 5 and 6 o'clock, it will be found very difficult to determine with sufficient accuracy the distance of the corresponding points on the respective paths.

In reference to this eclipse, it will be interesting to observe whether any visible impression is made on the sun's limb at those places which are situated about the extremity of the penumbra. Such places will be found a little to the west, southwest, and south of London.

* Communicated by the Author. 